\title{
Comparative Study of Protein Immobilization Properties on Calixarene Monolayers
}

\author{
Hongxia Chen ${ }^{1}$, Minsu Lee ${ }^{2}$, Sungwook Choi ${ }^{3}$, Jae-Ho Kim ${ }^{3}$, Heung-Jin Choi ${ }^{4}$, \\ Sung-Hoon Kim ${ }^{4}$, Jeabeom Lee ${ }^{5}$ and Kwangnak Koh ${ }^{5 \text {, * }}$ \\ ${ }^{1}$ College of Pharmacy, Pusan National University, Pusan 609-735, Korea; \\ E-mail: chenhongxia@pusan.ac.kr \\ ${ }^{2}$ Seed Biochips, Chung-Buk, 363-883, Korea; E-mail: antilee@naver.com \\ ${ }^{3}$ Department of Molecular Science and Technology, Ajou University, Suwon 442-749, Korea; \\ E-mail: jhkim@ajou.ac.kr \\ ${ }^{4}$ Department of Textile System Engineering, Kyungpook National University, Taegu 702-701, Korea; \\ E-mail: choihj@knu.ac.kr; shokim@knu.ac.kr \\ ${ }^{5}$ Department of Nanomedical Engineering, Pusan National University, Pusan 609-735, Korea; \\ E-mail: jeabeom@pusan.ac.kr
}

* Author to whom correspondence should be addressed. E-mail: koh@ pusan.ac.kr

Received: 19 June 2007 / Accepted: 28 June 2007 / Published: 29 June 2007

\begin{abstract}
Three calix[4]arene (Cal-4) derivatives of which contain ethylester (1), carboxylic acid (2), and crownether (3) at the lower rim with a common reactive thiol at the upper rim were synthesized and constructed to self-assembled monolayers (SAMs) on Au films. After spectroscopic characterization of monolayers, the interaction between Cal-4 and surface confined bovine serum albumin (BSA) in the SAMs was analyzed by surface plasmon resonance (SPR). The estimated surface concentration of BSA on the Cal-4 SAM with crownether group was the highest among the three Cal-4 derivatives. Anti-hIgG and hIgG pair was employed for the investigation of protein-protein interaction. Molecular interaction between anti-hIgG and $\mathrm{hIgG}$ can be detected in a concentration range of 10 $\mathrm{pg} / \mathrm{mL}$ to $200 \mathrm{pg} / \mathrm{mL}$ on the Cal-4 derivative 3 SAM modified SPR chip.
\end{abstract}

Keywords: Calix[4]arene; Self-assembled monolayer; Linker system; anti-hIgG; Biosensor. 


\section{Introduction}

Protein adsorption onto the surface of a foreign material is the initial event for the diverse application such as advanced biosensors, biochips, bioreactors and many diagnostic techniques. For this reason, it is very important to construct well-characterized linker system that can immobilize protein efficiently [1]. It is well known that calix[4]arene (Cal-4) has been used in the design and synthesis of artificial receptors for cations, anions and neutral organic molecules [2-7]. In particular, the lower or upper rim of the Cal-4 molecule can be modified to achieve more sophisticated structures to bind specific guest molecules [8-10]. Therefore, Cal-4 derivatives can be used as an artificial linker system for protein immobilization. For the construction of well-characterized linker layer, selfassembled monolayer (SAM) technique can be applied to the organization of artificial linker molecules on the solid substrates surface. This SAM technique guarantees each molecule to exhibit its original function on the surface [11]. SPR technique is a essential analysis instrument to characterized the immobilization of artificial linker molecules and the interaction of protein-protein on the molecular linker system. Currently, surface plasmon resonance (SPR) based protein-protein interaction on $\mathrm{Au}$ substrate has been extensively studied and widely applied to develop protein chips [12-14].

Our research purpose is a SPR based fundamental study of protein immobilization properties on artificial linker system in order to increase the amount of immobilized receptor proteins. For this purpose, three different Cal-4 derivatives containing ethylester (1), carboxylic acid (2), and crownether (3) at the lower rim were synthesized and applied to linker layer for protein immobilization system. Self-assembly technique was utilized to construct a well-characterized linker layer and then, Cal-4 monolayer formation process was investigated with SPR spectroscopy. The characterization of Cal-4 derivative SAMs was monitored by FT-infrared reflection absorption spectroscopy (FTIR-RAS), atomic force microscopy (AFM) image, and electrochemical analysis. Immobilization of bovine serum albumin (BSA) as a standard protein on the Cal-4 linker system was measured. The comparison of surface concentration of BSA on the Cal-4 linker system monolayers were calculated by simulation of experimental SPR data [15]. In addition, the protein-protein interaction was observed using anti-hIgG and $\mathrm{hIgG}$ to evaluate application potential of the artificial linker systems to protein chip.

\section{Experimental}

\subsection{Chemicals and Reagents}

Protein A, anti-hIgG, hIgG, BSA and phosphate-buffered saline (PBS) were obtained from Sigma Chemical Co. (St. Louis, MO, USA). All other reagents including LiOH, chloroform, methanol, and Acetone were purchased from Aldrich Chemical Co. (Milwaukee, WI, USA). Cal-4 derivative 1 (ethylester) and $\mathbf{2}$ (carboxylic acid) were synthesized. Cal-4 derivative $\mathbf{3}$ (crownether) was obtained from Proteogen Co. (ProLinker ${ }^{\mathrm{TM}}$, Seoul, Korea). A Milli-Q grade $(>18.2 \mathrm{~m} \Omega \cdot \mathrm{cm})$ water was used for the preparation of buffer solutions. 

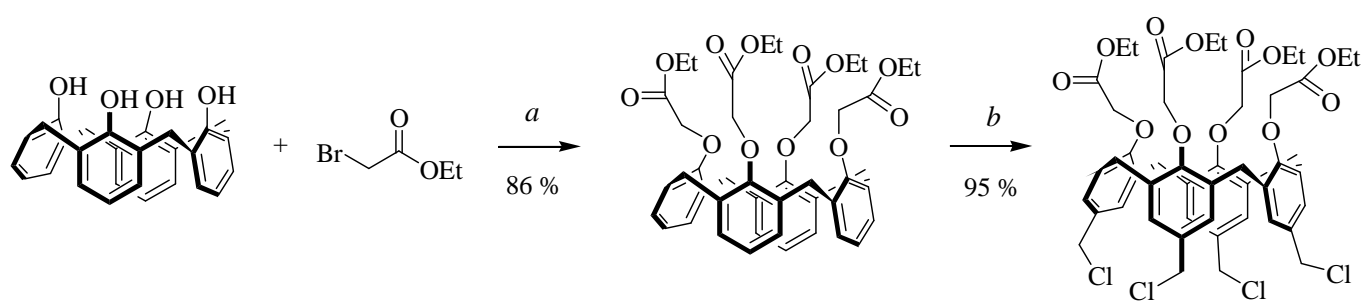

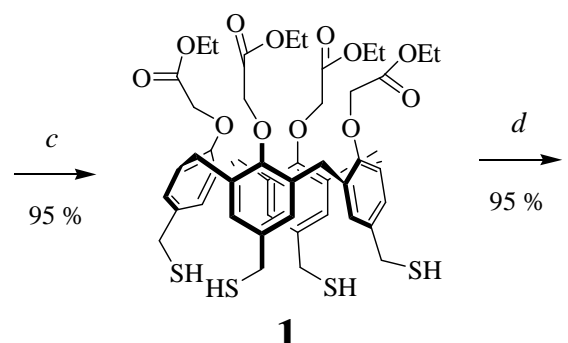

1

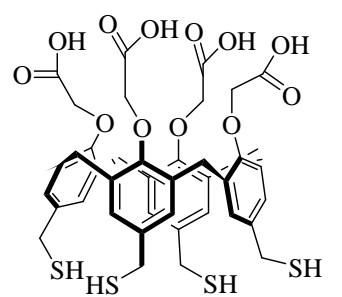

2

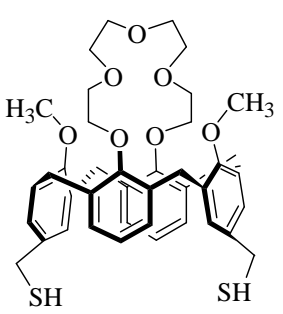

3

Reagents and Conditions: (a) $\mathrm{Na}_{2} \mathrm{CO}_{3}$, acetonitrile, reflux, $24 \mathrm{~h}$; (b) $\mathrm{CH}_{3} \mathrm{OCH}_{2} \mathrm{Cl}, \mathrm{SnCl}_{4}, \mathrm{CH}_{2} \mathrm{Cl}_{2},-15 ; \mathbb{E}, 3 \mathrm{~h}$; (c) $(1)\left(\mathrm{H}_{2} \mathrm{~N}\right)_{2} \mathrm{Cs}$, DMF, (2) $1 \mathrm{~N} \mathrm{NaOH}$; (d) $\mathrm{LiOH}, \mathrm{H}_{2} \mathrm{O}-\mathrm{MeOH}$.

Proteogen Inc. (Seoul, Korea)

Figure 1. Synthetic scheme and structure of Cal-4 derivative 1, 2 and $\mathbf{3 .}$

\subsection{Synthesis and Characterization of Cal-4 Derivative 1 and 2}

Cal-4 derivative 1 was synthesized according to the modified literature procedure [16]. A mixture of tetrakis(chloromethyl)Cal-4 (216 mg, $0.22 \mathrm{mmol})$ and thiourea $(200 \mathrm{mg}, 2.6 \mathrm{mmol})$ was dissolved in DMF $(15 \mathrm{~mL})$. The mixture was stirred at room temperature overnight under $\mathrm{N}_{2}$. The solvent was removed by vacuum distillation at $100{ }^{\circ} \mathrm{C}$. The residue was dissolved in $20 \mathrm{~mL}$ of $1 \mathrm{M}$-aquoues $\mathrm{Na}_{2} \mathrm{CO}_{3}$. The product was extracted with $\mathrm{CH}_{2} \mathrm{Cl}_{2}(20 \mathrm{~mL} \times 3)$. The combined organic layer was dried over $\mathrm{MgSO}_{4}$, filtered, and concentrated to dryness to give glassy solid (200 mg, $94 \%$ ). The product was characterized by ${ }^{1} \mathrm{H}$ and ${ }^{13} \mathrm{C}$ NMR (400 MHz and $100 \mathrm{MHz}, \mathrm{CD}_{3} \mathrm{OD}$, Bruker Co., USA) [17]. Cal-4 derivative 2 (carboxylic acid) was converted from Cal-4 derivative 1 (ethylester) by treatment of $0.1 \mathrm{M}$ LiOH for $3 \mathrm{~h}$ (Figure 1).

\subsection{Formation and Characterization of Cal-4 Derivative SAMs}

A microscope cover glass (Matsunami, Japan) with Au layer was used as a substrate for the formation of Cal-4 derivative SAMs. Au film (about $50 \mathrm{~nm}$ thickness) was deposited on the cover glass by the sputter coating system (E5000, Polaron Co., U.K.) under conditions of $2.0 \times 10^{-2}$ mbar and 20 $\mathrm{mA}$ for $180 \mathrm{~s}$. The Au chips were cleaned in piranha solution $\left(30 \% \mathrm{H}_{2} \mathrm{O}_{2}\right.$ : concentrated $\mathrm{H}_{2} \mathrm{SO}_{4}=1: 3$, $\mathrm{v} / \mathrm{v}$ ) for $15 \mathrm{~s}$ and carefully rinsed with DW, methanol and acetone, sequentially. The Au chips were then dried in a $\mathrm{N}_{2}$ stream.

Cal-4 derivative 1 was prepared to $0.1 \mathrm{mM}$ in chloroform:methanol = 1:9 (v/v) solution mixture for the formation of its SAM on Au surface. The 1 SAM was formed by immersing the Au chips into Cal-4 derivative 1 solution for $6 \mathrm{~h}$. The immobilization process was monitored by SPR spectroscopy. After the immobilization process, the sensor chip was rinsed with the same chloroform-methanol 
solution mixture and methanol and then dried under $\mathrm{N}_{2}$ stream.

Cal-4 derivative 2 SAM was converted from Cal-4 derivative 1 SAM through the hydrolysis of ethylene group by treatment of $\mathrm{LiOH}$ for $3 \mathrm{~h}$ (Figure 1). Cal-4 derivative 3 was prepared to $1 \mathrm{mM}$ in chloroform:methanol = 1:3(v/v) mixture for the formation of SAM on Au surface.

After rinsing with the same solvent of SAM formation process and drying under $\mathrm{N}_{2}$ gas stream, SAMs of Cal-4 derivatives were characterized by FTIR-RAS, AFM and cyclic voltammetry (CV).

The FTIR-RAS spectra were measured with a resolution of $2 \mathrm{~cm}^{-1}$. The glazing angle was maintained at $80^{\circ}$ and a p-polarized IR beam was used as the light source. AFM images were collected by the contact mode. The silicon nitride cantilevers had a nominal spring constant of about $0.067 \mathrm{~N} / \mathrm{m}$. The scanning parameters were adjusted to provide clear images, revealing the affects of SAM on the deposited gold surface. For electrochemical measurements, $\mathrm{Au}, \mathrm{Pt}$, and $\mathrm{Ag} / \mathrm{AgCl}$ were used as the working, counter, and reference electrodes, respectively. The electrochemical reductive desorption of the Cal-4 derivatives from the electrode was performed in $0.5 \mathrm{M} \mathrm{KOH}$ solution by scanning from 0 to $1.2 \mathrm{~V}$ at a scan rate of $50 \mathrm{mV} / \mathrm{s}$. To calculate the real area of the electrode, $\mathrm{CV}$ measurements for the $\mathrm{Au}$ electrode were carried out in $0.5 \mathrm{M} \mathrm{H}_{2} \mathrm{SO}_{4}$ with a scan rate of $200 \mathrm{mV} / \mathrm{s}$.

\subsection{SPR Spectroscopic Measurement}

SPR spectroscopic measurements for the monolayer formation of Cal-4 derivatives and BSA immobilization were performed by homemade SPR system based on the traditional Kretschmann configuration [18]. In addition, proteinchip application using Cal-4 derivative SAMs as a molecular linker system was measured by commercial SPR (K-MAC Co., SpectraBio 2000, Taejon, Korea). A schematic diagram of the homemade SPR system and a sensor chip configuration is shown in Figure 2.

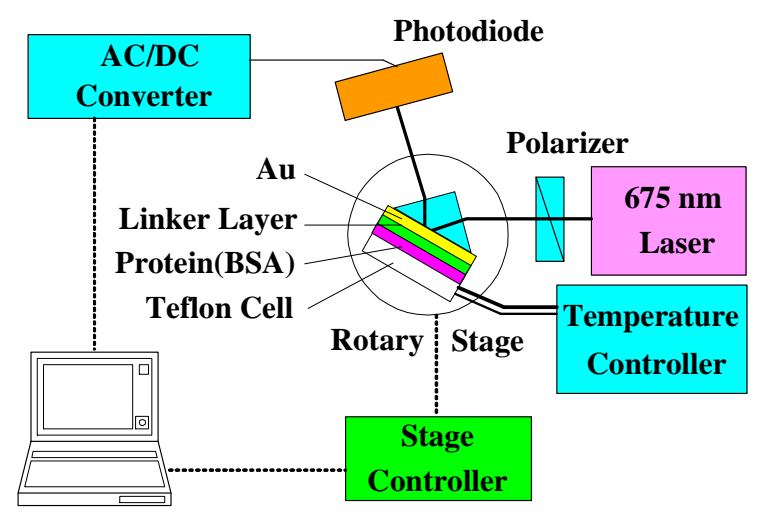

(a)

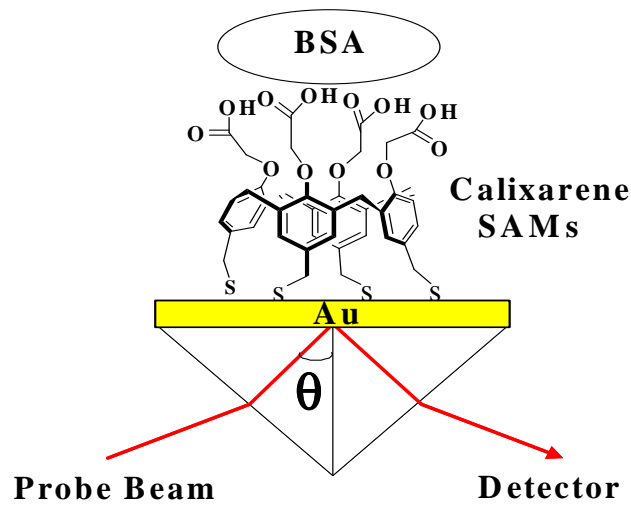

(b)

Figure 2. Schematic diagram of (a) the homemade SPR system and (b) a sensor chip configuration.

Laser diode (LD, $\lambda_{\max }=675 \mathrm{~nm}$ ) was used as the light source. Reflected intensity of light by a way of the polarizer and the prism was measured with the photodiode detector (ANDO Electric Co. Ltd., AQ-1976, Kanagawa, Japan). The incident angle into the prism varied with the motorized rotary stage and its controller (Suruga Seiki, D80, Shizuoka, Japan). During the SPR measurements, the temperature was kept at $25 \pm 0.1^{\circ} \mathrm{C}$ by temperature controlling system with Peltier-module. The signal from photodiode was converted through a signal process board (K-MAC Co., Spectra View 
2000, Taejon, Korea) and could be interfaced with a computer. The angle resolution of the SPR system that was determined by the resolution of motorized rotary stage was 0.004 degree.

\subsection{BSA Immobilization and Theoretical Calculation}

Observation of protein immobilization and theoretical calculation of immobilized proteins amount on the self-assembled artificial linker layers were performed using BSA as a standard protein. The concentration of BSA was $0.5 \mu \mathrm{M}$ in PBS buffer $(\mathrm{pH}$ 7.4). The immobilization process of BSA was measured by SPR. The surface concentration of immobilized BSA was calculated according to a previously reported method [15]. The optical parameters that required to calculating the surface concentration of immobilized BSA were determined by simulation with experimental SPR data. The surface concentration of immobilized BSA on the surface was calculated by the following equation:

$$
\Gamma=3 d\left(n^{2}-n_{b}^{2}\right) /\left[\left(n^{2}+2\right)\left(r\left(n_{b}^{2}+2\right)-v\left(n_{b}^{2}-1\right)\right)\right]
$$

Where, $\Gamma$ and $d$ are surface concentration of the adsorbed molecules and the thickness of the adsorbed layer, respectively. $n_{b}$ and $n$ are the refractive index of the buffer solution and of the adsorbed layer, respectively. $r$ and $v$ are the specific refractivity of BSA $(0.243 \mathrm{ml} / \mathrm{g})$ and the partial specific volume of BSA deposited on the linker layer $(0.729 \mathrm{ml} / \mathrm{g})$.

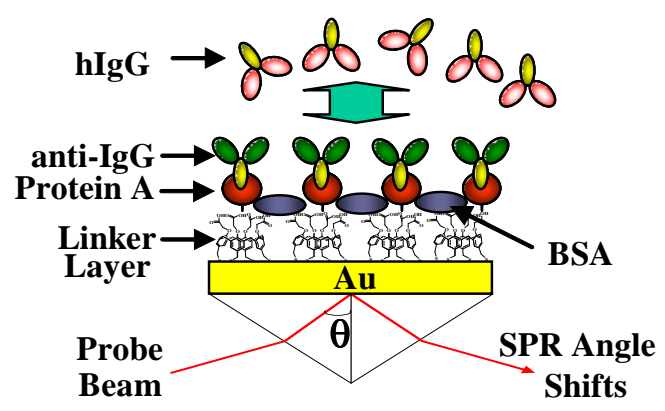

Figure 3. Schematic diagram of protein-protein interaction between hIgG and anti-hIgG on Cal-4 linker system confined Au surface.

\subsection{Application to Biochip}

To evaluate the application potential of Cal-4 derivatives as a molecular linker system to proteinchip, the measurement of molecular interaction between anti-hIgG and hIgG, was investigated by SPR. Anti-hIgG can be well oriented onto the self-assembled protein A layer, since it's well known that protein A binds to the Fc region of IgG [19-21]. A schematic diagram of a sensor chip configuration is shown in Figure 3. Proteins including protein A, anti-hIgG, and BSA were immobilized on the gold surface with Cal-4 derivative SAMs respectively. The concentration of protein A was $500 \mu \mathrm{g} / \mathrm{mL}$ in PBS solution ( $\mathrm{pH}$ 7.4). The anti-hIgG solution for the immobilization of probe protein was prepared with $150 \mu \mathrm{g} / \mathrm{mL}$ concentration in PBS solution ( $\mathrm{pH} 7.4$ ). For blocking the nonspecific binding of hIgG onto the site of Cal-4 derivatives SAMs without anti-hIgG, the chip was treated in $30 \mathrm{mg} / \mathrm{mL}$ BSA in PBS solution ( $\mathrm{pH} 7.4$ ).

SPR angle shifts induced by the interaction between anti-hIgG and hIgG were measured by commercial SPR (K-MAC Co., SpectraBio 2000, Taejon, Korea). The measured concentration of hIgG 
solution ranged from $5.0 \mathrm{pg} / \mathrm{mL}$ to $10 \mu \mathrm{g} / \mathrm{mL}$ in PBS solution ( $\mathrm{pH} 7.4)$. The results were averaged after measurement and uniformly smoothed by adjacent averaging.

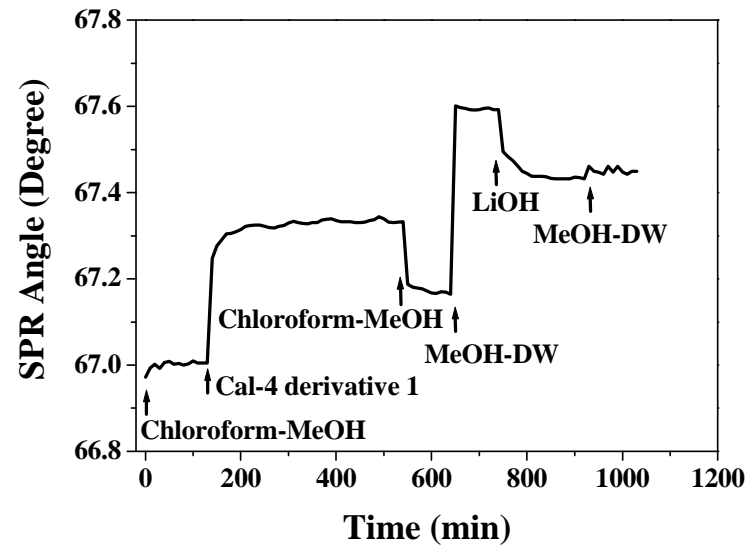

(a)

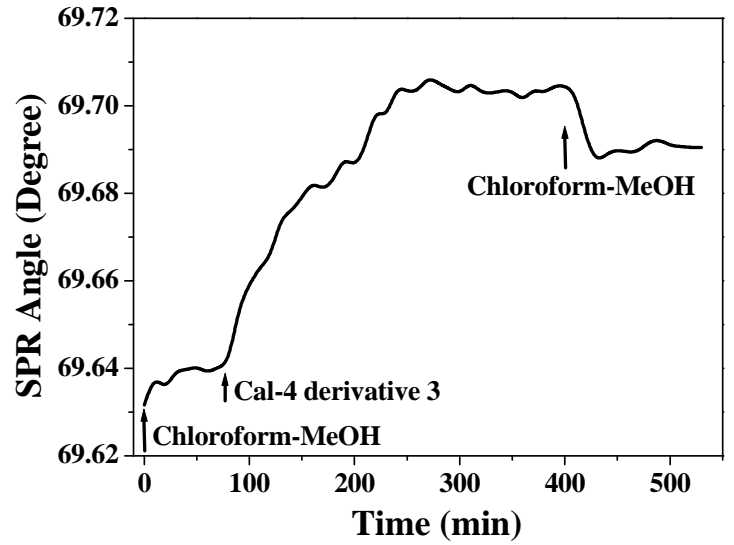

(b)

Figure 4. SPR angle shifts according to the immobilization of Cal-4 derivative SAMs. (a) Cal-4 derivative 1 and 2 SAMs, (b) Cal-4 derivative 3 SAM.

Table 1. FTIR-RAS spectra assignment of Cal-4 derivative SAMs.

\begin{tabular}{cccc}
\hline \multirow{2}{*}{$\begin{array}{c}\text { Stretching } \\
\text { Mode }\end{array}$} & $\begin{array}{c}\text { Cal-4 derivative } \\
\text { 1 SAM }\end{array}$ & $\begin{array}{c}\text { Cal-4 derivative } \\
\text { 2 SAM }\end{array}$ & $\begin{array}{c}\text { Cal-4 derivative } \\
\text { 3 SAM }\end{array}$ \\
\cline { 2 - 4 }$v(\mathrm{O}-\mathrm{H})$ & & 3546 & \\
$v_{\mathrm{a}}\left(\mathrm{CH}_{3}\right)$ & 2952 & & 2968 \\
$v_{\mathrm{a}}\left(\mathrm{CH}_{2}\right)$ & 2925 & 2925 & 2927 \\
$v_{\mathrm{S}}\left(\mathrm{CH}_{2}\right)$ & 2858 & 2860 & 2854 \\
$v(\mathrm{C}=\mathrm{O})$ & 1764 & 1759 & \\
$v(\mathrm{C}=\mathrm{C})$ & 1473 & 1473 & 1474 \\
$\delta\left(\mathrm{CH}_{3}\right)$ & 1377 & & 1373 \\
$v\left(\mathrm{sp}^{2} \mathrm{C}-\mathrm{O}\right)$ & 1207 & 1201 & 1203 \\
$v\left(\mathrm{sp}^{3} \mathrm{C}-\mathrm{O}\right)$ & & & 1149 \\
\hline
\end{tabular}

\section{Results and Discussion}

\subsection{Formation and Characterization of Cal-4 Derivative SAMs}

In the immobilization process of Cal-4 derivative $\mathbf{1}$ on $\mathrm{Au}$ surface, as the number of immobilized molecule increased, SPR angle shifts were gradually increased and saturated at inner $10 \mathrm{~h}$. After that, 
the Cal-4 derivative 1 SAM (ethylester) was consecutively converted to Cal-4 derivative 2 SAM (carboxylic acid) by treatment of $\mathrm{LiOH}$ solution for $3 \mathrm{~h}$ (Figure 4(a)). On the other hand, the immobilization process of Cal-4 derivative 3 on Au surface was measured by SPR. SPR angle shifts caused by immobilization of Cal-4 derivative 3 were gradually increased and saturated at inner $8 \mathrm{~h}$ (Figure 4(b)).

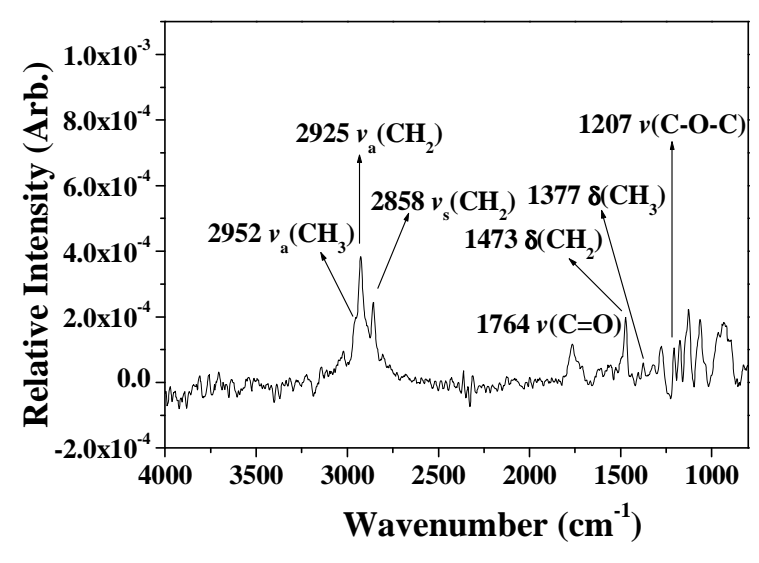

(a)

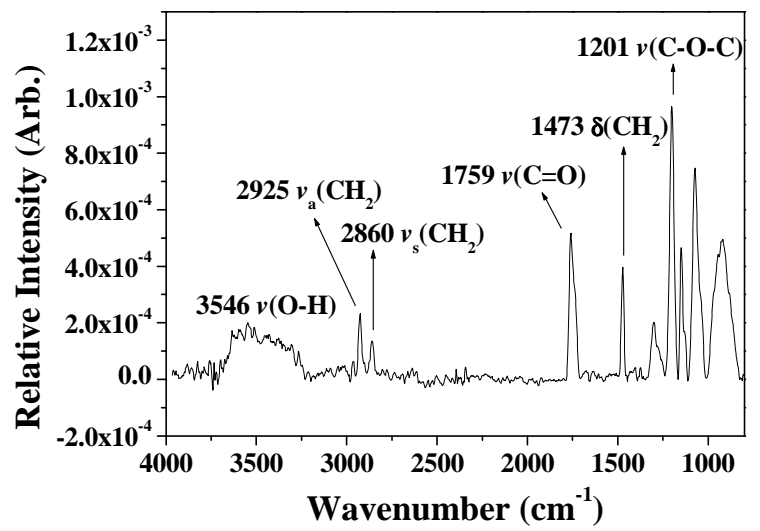

(b)

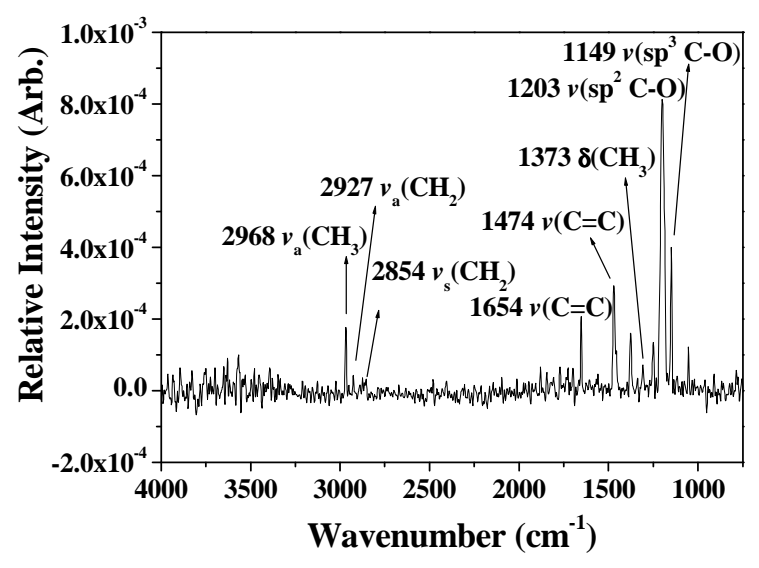

(c)

Figure 5. FTIR-RAS spectra of (a) Cal-4 derivative 1 SAM, (b) Cal-4 derivative 2 SAM, and (c) Cal4 derivative 3 SAM on Au surface.

The formation of each Cal-4 derivative SAM was characterized by FTIR-RAS, AFM, and CV. Figure 5 and Table 1 show the FTIR-RAS spectra and assignment of three Cal-4 derivative SAMs on $\mathrm{Au}$ surface. In the FTIR-RAS spectra, we confirmed the typical absorption spectra of Cal-4 derivative SAMs on Au surface. In particular, the formation of Cal-4 derivative 2 SAM with carboxylic acid group from Cal-4 derivative $1 \mathrm{SAM}$ was verified by appearance of $\mathrm{v}(\mathrm{OH})$ stretching at $3546 \mathrm{~cm}^{-1}$ and absence of $\delta\left(\mathrm{CH}_{3}\right)$ stretching at $1377 \mathrm{~cm}^{-1}$ due to the elimination of ethylester group. In addition, after removing ethylester group of Cal-4 derivative $1 \mathrm{SAM}$, the peak intensity of $\mathrm{v}_{\mathrm{s}}\left(\mathrm{CH}_{2}\right)$ and $\mathrm{v}_{\mathrm{a}}\left(\mathrm{CH}_{2}\right)$ stretching mode was decreased in the FTIR-RAS spectra of Cal-4 derivative 2 SAM. FTIR-RAS spectra of Cal-4 derivative $3 \mathrm{SAM}$ on Au surface showed $v\left(\mathrm{sp}^{2} \mathrm{C}-\mathrm{O}\right)$ stretching at $1203 \mathrm{~cm}^{-1}$ due to 
crownether group of Cal-4 derivative SAM.

Table 2. RMS Roughness of Cal-4 derivative SAMs on Au surface.

\begin{tabular}{cc}
\hline Monolayer & RMS Roughness $(\AA)$ \\
\hline Bare Au & 20.1 \\
Cal-4 derivative 1 SAM & 35.1 \\
Cal-4 derivative 2 SAM & 39.1 \\
Cal-4 derivative 3 SAM & 18.1 \\
\hline
\end{tabular}

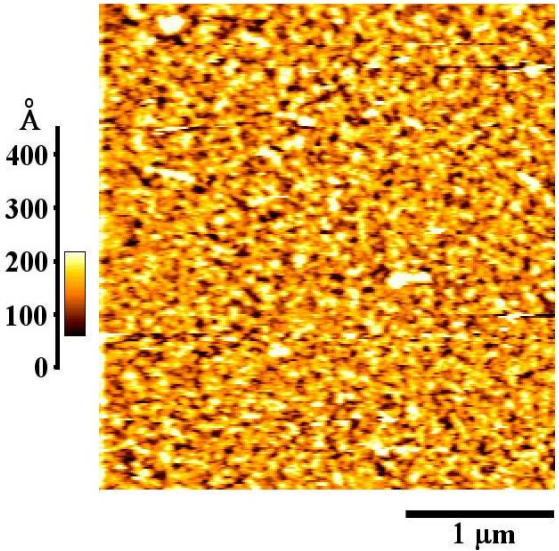

(a)

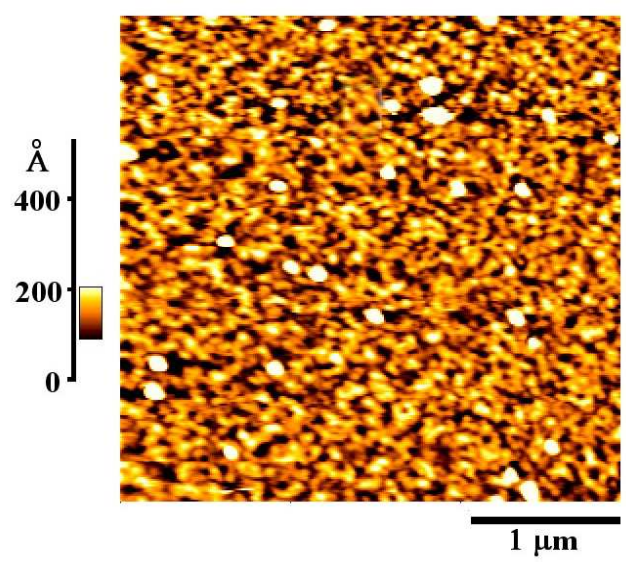

(c)

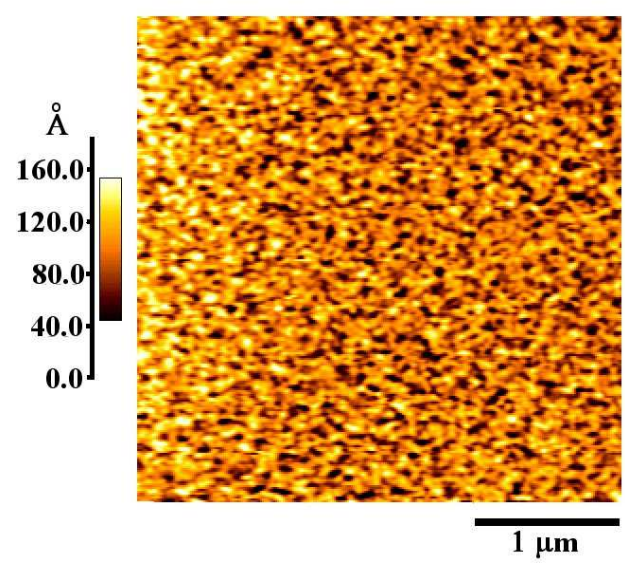

(b)

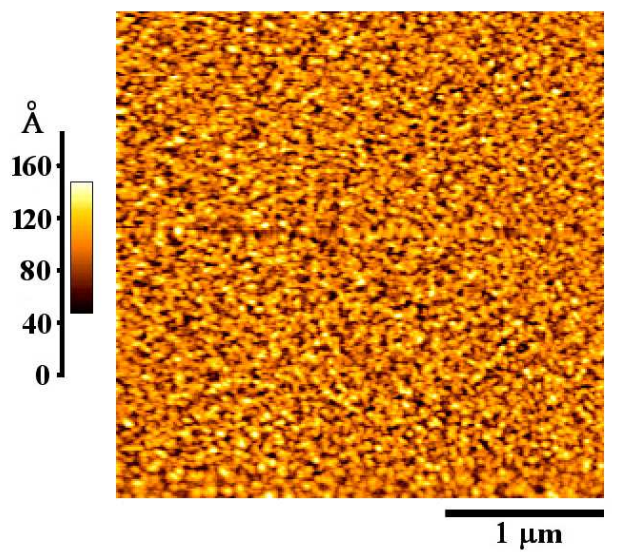

(d)

Figure 6. AFM images of (a) Bare Au, (b) Cal-4 derivative 1 SAM, (c) Cal-4 derivative 2 SAM, and (d) Cal-4 derivative 3 SAM.

The AFM images showed the surface geometry of bare Au and Cal-4 derivative-modified $\mathrm{Au}$ surface (Figure 6). In comparison with bare Au surface, the Cal-4 derivative-modified Au surface 
showed a marked difference. The images of Au surface with Cal-4 derivative 1 and 2 SAMs composed of a much larger grain size than that of bare Au surface. While, in case of Cal-4 derivative 3 SAM, the images of Au surface with Cal-4 derivative 3 SAM showed a little smaller grain size than that of bare Au surface.

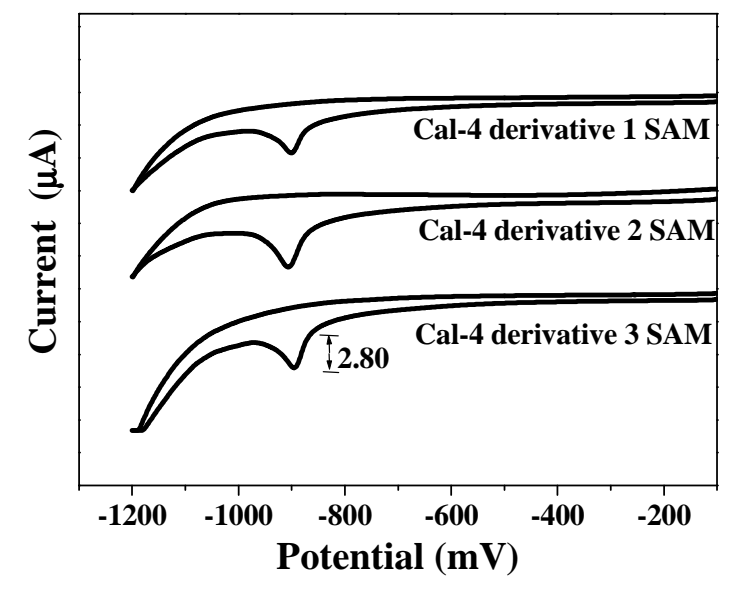

Figure 7. Reductive desorption peaks of Cal-4 derivative SAMs on the Au electrode surface.

Table 3. Surface coverage of Cal-4 derivative SAMs on Au electrode surface.

\begin{tabular}{cc} 
Monolayer & $\begin{array}{c}\text { Surface Coverage }(\Gamma) \\
\left(\times 10^{-11} \mathrm{~mole} / \mathrm{cm}^{2}\right)\end{array}$ \\
\hline Cal-4 derivative 1 SAM & 7.076 \\
Cal-4 derivative 2 SAM & 6.647 \\
Cal-4 derivative 3 SAM & 22.092 \\
\hline
\end{tabular}

In the RMS value that present the roughness degree of one of the most general and most useful roughness parameters, the RMS roughness of the bare Au surface was $20.1 \AA$, while those of Cal-4 derivative SAMs were 35.1 (Cal-4 derivative 1 SAM), 39.1 (Cal-4 derivative 2 SAM), and $18.1 \AA$ (Cal-4 derivative 3 SAM), respectively (Table 2). These changes in RMS roughness of Cal-4 derivative-modified Au surface strongly support the formation of SAM. In particular, the Au surface with Cal-4 derivative 3 SAM showed a little smaller RMS roughness value than that of bare $\mathrm{Au}$ surface. This may be explained by the decrease of RMS roughness value due to the densely packed arrangement of Cal-4 derivative 3 SAM. In addition, this result was supported by regular and small grain size in AFM image (Figure 6(d)).

In some previous studies, the formation mechanism of alkanethiol monolayers on Au substrates has been proposed [22-24]. Though the Cal-4 derivatives have different number of -SH group in the upper rim of Cal-4, the formation of three Cal-4 derivative SAMs on Au substrates can be explained by the same mechanism. The properties of the electrode with Cal-4 derivative SAMs can be estimated by submitting the electrode to reductive desorption experiments. Figure 7 shows the reductive desorption 
peaks of Cal-4 derivative SAMs on the Au electrode. This peak has been attributed to the reductive desorption of thiolated compounds that are chemisorbed to $\mathrm{Au}$.

After assuming that all thiolated compounds are reduced/oxidized in the CV experiments, the surface coverage can be determined from the reductive desorption data [23-25]. Accounting for the surface roughness of the Au electrode, the surface coverage $(\Gamma)$ of the Cal-4 derivative SAMs at the Au electrode were calculated from the integrated area under the reduction peak (Table 3). These calculated values effectively indicate the relative packing degree of each Cal-4 derivative SAM on the Au surface.

\subsection{BSA Immobilization and Theoretical Calculation}

In the study of protein immobilization process using BSA, as the adsorbed BSA molecule increased on Au surface, SPR angle shifts were gradually increased and saturated at inner $5 \mathrm{~h}$ (Figure 8). SPR angle shifts $(\Delta \theta)$ that caused by the immobilization of BSA in PBS solution were $0.06^{\circ}$ (Cal-4 derivative $1 \mathrm{SAM}), 0.10^{\circ}$ (Cal-4 derivative $2 \mathrm{SAM}$ ), and $0.147^{\circ}$ (Cal-4 derivative $3 \mathrm{SAM}$ ), respectively.

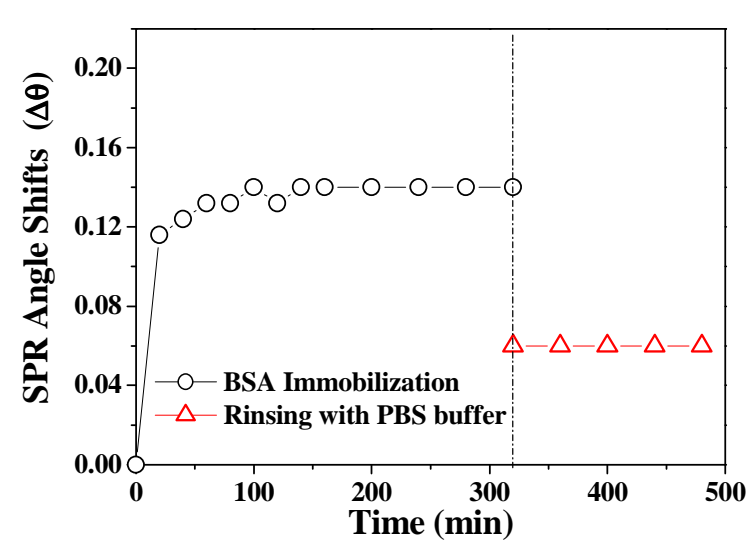

(a)

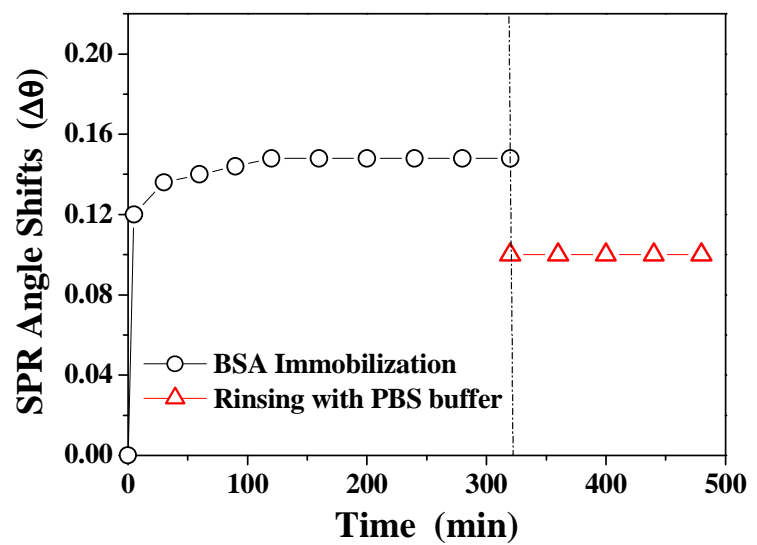

(b)

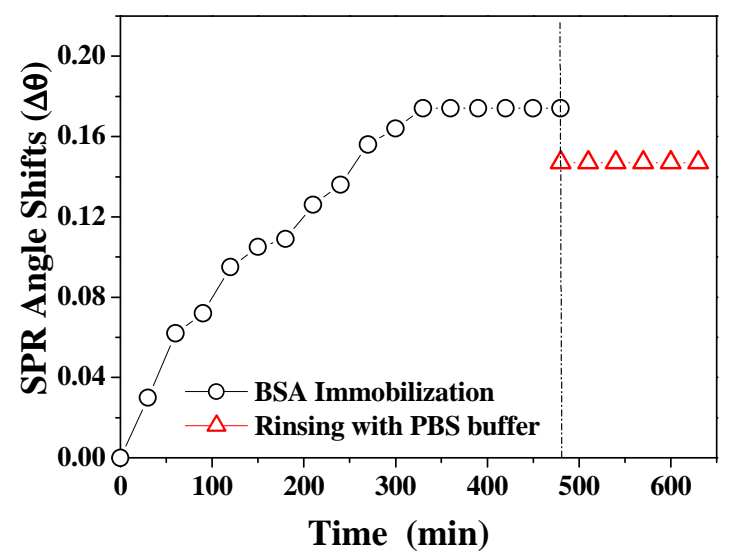

(c)

Figure 8. SPR angle shifts according to the immobilization of BSA on (a) Cal-4 derivative 1 SAM, (b) Cal-4 derivative 2 SAM, and (c) Cal-4 derivative 3 SAM. 
After immobilization of BSA, geometrical morphology and granule size of Au surface with BSAmodified Cal-4 derivative SAMs were changed remarkably (Figure 9). The images of Au surface with BSA-modified Cal-4 derivative 2 and $\mathbf{3}$ SAMs showed a much larger grain size than that of the other $\mathrm{Au}$ surface with BSA-modified Cal-4 derivative 1 SAM. In particular, the Au surface with BSAmodified Cal-4 derivative 3 SAM showed large and regular grain size. These results strongly support that on the Cal-4 derivative 3 SAM, the amount of adsorbed BSA is the largest and also the immobilization characteristic of BSA is excellent.

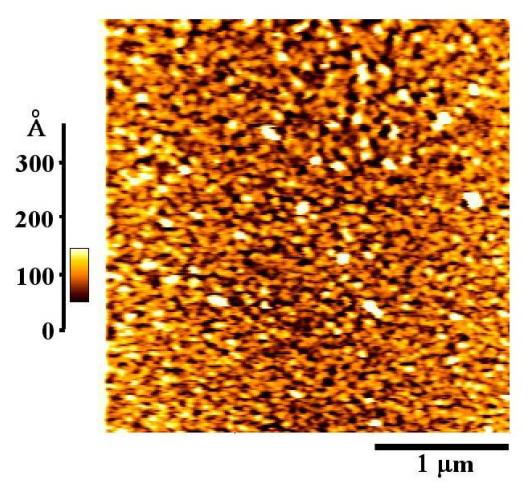

(a)

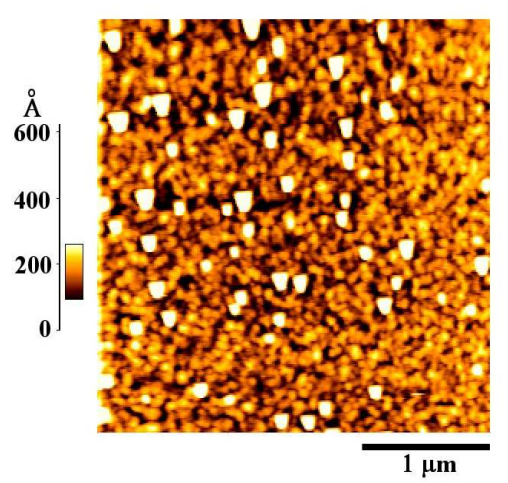

(b)

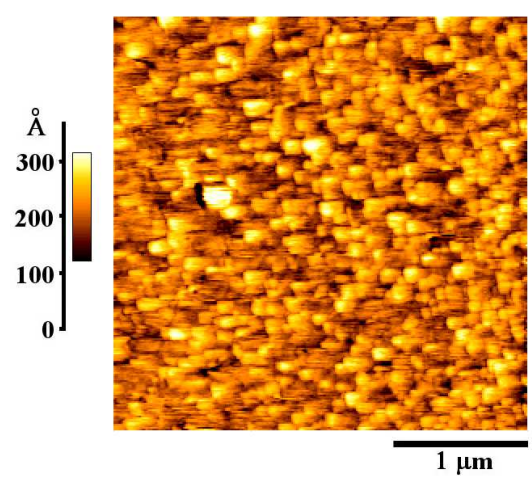

(c)

Figure 9. AFM images of (a) BSA-immobilized Cal-4 derivative 1 SAM, (b) BSA-immobilized Cal-4 derivative 2 SAM, and (c) BSA-immobilized Cal-4 derivative 3 SAM.

In the AFM image, the RMS roughness of each Cal-4 derivative SAMs was $22.7 \AA$ (Cal-4 derivative 1 SAM), $55.7 \AA$ (Cal-4 derivative 2 SAM), and $45.2 \AA$ (Cal-4 derivative 3 SAM), respectively. In case of Cal-4 derivative 2 and 3 SAMs, their carboxylic acid group and crown moiety can interact with amine or ammonium groups of protein, strongly. Therefore, a large amount of BSA was immobilized on Cal-4 derivative 2 and 3 SAMs, accordingly their RMS roughness increased after BSA immobilization. In addition, in case of Cal-4 derivative 3 SAM, hydrophobic interactions between hydrophobic residue of protein and methoxy group of the linker molecules may also be involved in protein immobilization. On the contrary, Cal-4 derivative 1 SAM doesn't have any effective terminal group to interact with protein. Thus it was expected that the amount of immobilized BSA would be small. In AFM measurement results of BSA-immobilized Cal-4 derivative 1 SAM, the reason of relative small RMS roughness can be explained that only a small amount of BSA was immobilized on SAM and also they filled in a groove of SAM surface.

The optical parameters that required to calculating the surface concentration of immobilized BSA were determined by simulation with experimental SPR data. Figure 10 showed the experimental and calculated SPR curves of Cal-4 derivative SAMs according to the immobilization of BSA. The surface concentration of immobilized BSA on the Au surface with Cal-4 derivative SAMs can be calculated and compared each other [15].

Table 4 shows the surface concentration of BSA and thickness change on the Cal-4 derivative SAMs. The surface concentration of immobilized BSA on the Cal-4 derivative SAMs was $98 \mathrm{ng} / \mathrm{cm}^{2}$ (Cal-4 derivative $1 \mathrm{SAM}$ ), $163 \mathrm{ng} / \mathrm{cm}^{2}$ (Cal-4 derivative $2 \mathrm{SAM}$ ), and $184 \mathrm{ng} / \mathrm{cm}^{2}$ (Cal-4 derivative 3 
SAM), respectively. Among the three Cal-4 derivative SAMs, Cal-4 derivative 3 SAM showed the most excellent characteristic as an artificial linker system for protein immobilization. Although Cal-4 derivative SAMs were formed on the commonly deposited Au surface not the Au (111) crystal, the surface concentration of immobilized BSA on the Cal-4 derivative 3 SAM is similar to that of wellordered alkanethiol SAM on Au (111) surface [26]. These results indicate that Cal-4 derivative 3 SAM has practical advantage for protein immobilization.

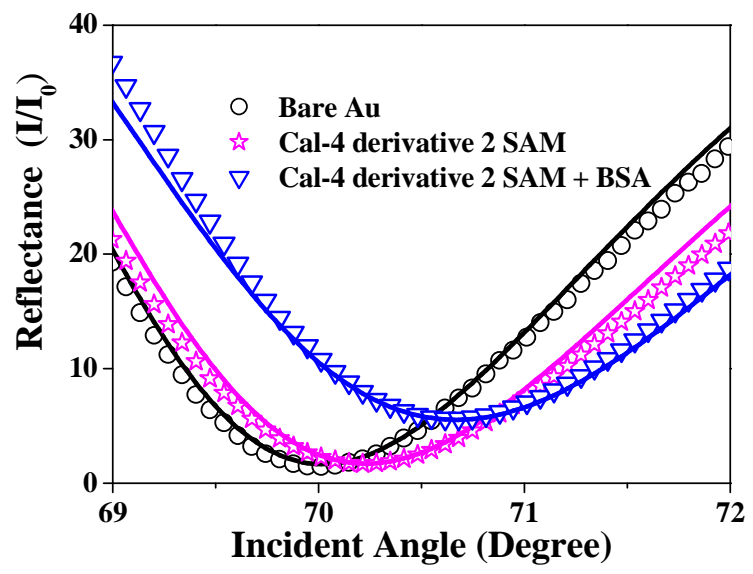

(a)

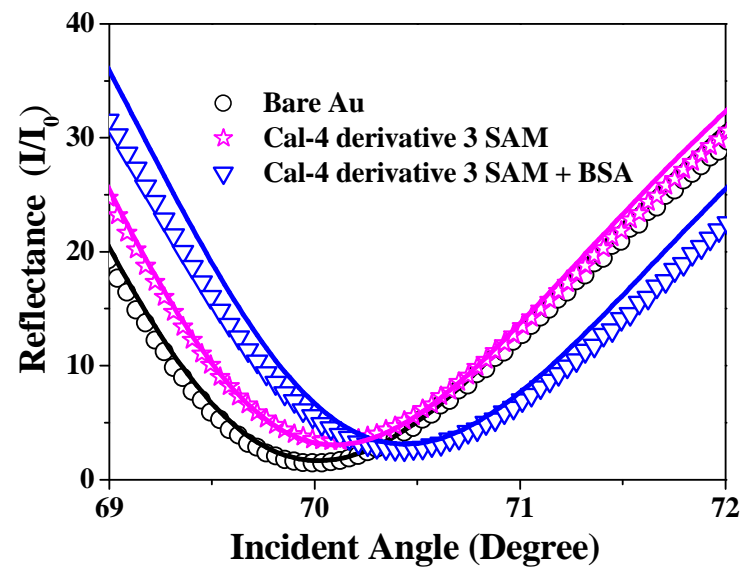

(b)

Figure 10. Experimental curves (symbol) and calculated SPR curves (line) of Au surface with Cal-4 derivative SAMs according to the immobilization of BSA; (a) Cal-4 derivative 2 SAM, (b) Cal-4 derivative 3 SAM.

Table 4. Surface concentration of the immobilized BSA and optical parameters determined by theoretical simulation.

\begin{tabular}{|c|c|c|c|c|c|c|c|c|c|c|}
\hline \multirow{2}{*}{ Monolayer } & \multicolumn{3}{|c|}{ Bare $\mathrm{Au}$} & \multicolumn{3}{|c|}{$\begin{array}{l}\text { Cal-4 Linker } \\
\text { Layer }\end{array}$} & \multicolumn{3}{|c|}{ BSA layer } & \multirow{2}{*}{$\begin{array}{c}\text { Surface } \\
\text { concentration } \\
\left(\mathrm{ng} / \mathrm{cm}^{2}\right)\end{array}$} \\
\hline & $n$ & $k$ & $d$ & $n$ & $k$ & $d$ & $n$ & $k$ & $d$ & \\
\hline $\begin{array}{c}\text { Cal-4 derivative } \\
1 \text { SAM }\end{array}$ & 0.233 & 3.8 & 48 & 1.60 & 0.24 & 1.4 & 1.45 & 0 & 1.3 & 98 \\
\hline $\begin{array}{c}\text { Cal-4 derivative } \\
2 \text { SAM }\end{array}$ & 0.227 & 3.8 & 48 & 1.59 & 0.15 & 1.1 & 1.45 & 0.05 & 2.4 & 163 \\
\hline $\begin{array}{c}\text { Cal-4 derivative } \\
\text { 3 SAM }\end{array}$ & 0.221 & 3.8 & 49 & 1.60 & 0.08 & 1.4 & 1.45 & 0 & 2.7 & 184 \\
\hline
\end{tabular}

$n$ is refractive index, $k$ is extinction coefficient, and $d$ is geometrical thickness (nm). 


\subsection{Application to Biochip}

To confirm the efficiency of protein immobilization on Au surface with Cal-4 linker system and of protein-protein interactions, SPR analysis using anti-hIgG and hIgG were carried out. The interaction between anti-hIgG and hIgG was represented by SPR angle shifts as a function of analyte protein concentration. For application to proteinchip, Cal-4 derivative 2 and 3 SAMs which showed good efficiency for immobilization of BSA were applied as an artificial linker system. Figure 11 shows the immobilization process of probe proteins such as protein A, anti-hIgG, BSA on the Cal-4 derivative 3 SAM. As the amount of immobilized probe protein increased, SPR angle shifts caused by binding of probe protein to the chip surface were gradually increased and saturated. The saturation time of each probe protein was $3 \mathrm{~h}$ (protein A and anti-hIgG) and $7 \mathrm{~h}$ (BSA), respectively.

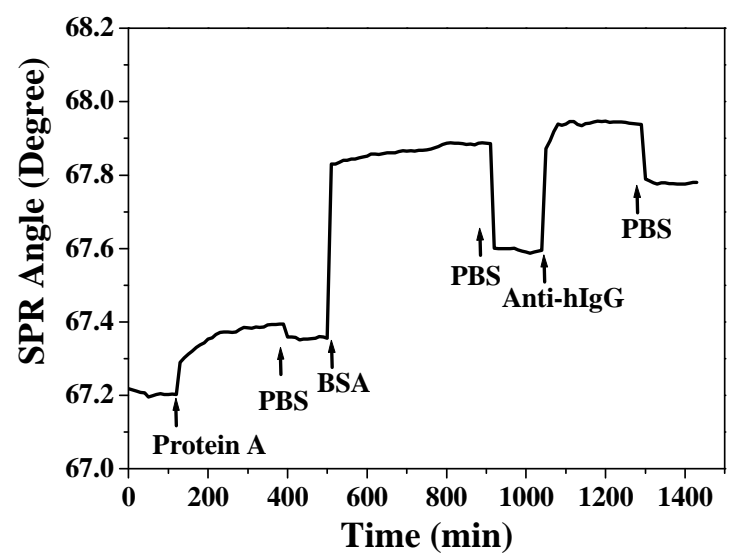

Figure 11. Sensogram of probe protein immobilization on the Cal-4 derivative 3 SAM.

Table 5. SPR angle shifts according to the protein (protein A, anti-hIgG and BSA) immobilization on the Cal-4 derivative SAMs.

\begin{tabular}{ccc}
\hline \multirow{2}{*}{ Proteins } & \multicolumn{2}{c}{ SPR Angle Shift $(\Delta \theta)$} \\
\cline { 2 - 3 } & $\begin{array}{c}\text { Cal-4 derivative } \\
\text { 2 SAM }\end{array}$ & $\begin{array}{c}\text { Cal-4 derivative } \\
\text { 3 SAM }\end{array}$ \\
\hline protein A $(500 \mu \mathrm{g} / \mathrm{mL})$ & 0.113 & 0.153 \\
BSA $(30 \mathrm{mg} / \mathrm{mL})$ & 0.475 & 0.239 \\
anti-hIgG $(150 \mu \mathrm{g} / \mathrm{mL})$ & 0.229 & 0.185 \\
\hline
\end{tabular}

Table 5 shows the SPR angle shifts according to the immobilization of each probe proteins on the Au surface with Cal-4 derivative 2 and 3 SAMs. In the immobilization process of protein A, SPR angle shifts in Cal-4 derivative 3 SAM was a little larger than that of Cal-4 derivative 2 SAM. On the other hand, in the BSA blocking and the immobilization process of anti-hIgG, SPR angle shifts in Cal-4 derivative 3 SAM was a little smaller than that of Cal-4 derivative 2 SAM. The sequential process for 
immobilization of probe proteins was successfully performed and estimated to have similar characteristics.

The molecular interaction between anti-hIgG and hIgG on the artificial linker system was measured by SPR. Figure 12 (a) shows the SPR angle shifts of the anti-hIgG immobilized sensor chip with Cal-4 derivative 3 SAM corresponding to various concentrations of hIgG in the PBS solution (pH =7.4). As the hIgG concentration increased, the SPR angle shift was gradually increased. This SPR angle shift arose from the molecular interaction between anti-hIgG and hIgG on the recognition interface with Cal-4 derivative 3 SAM.

Figure 12 (b) shows the dose-response curves of anti-hIgG immobilized sensor chip represented by SPR angle shifts according to variation of hIgG concentration. On the sensor chip with Cal-4 derivative 3 SAM, molecular interaction between anti-hIgG and hIgG can detectable at the concentration range from $10 \mathrm{pg} / \mathrm{mL}$ to $200 \mathrm{pg} / \mathrm{mL}$. While, in case of other one with Cal-4 derivative 2 SAM, detection range for the protein-protein interaction was from $100 \mathrm{pg} / \mathrm{mL}$ to $600 \mathrm{pg} / \mathrm{mL}$. With regard to the detection limit of conventional methods for the protein-protein interaction, which stay at the ng level, these results are quite remarkable. These results indicate that on the sensor chip with Cal4 derivative 3 SAM, probe protein was effectively immobilized and well organized for protein-protein interaction. In addition, these results strongly support that the protein chip with artificial linker system like as Cal-4 derivative SAMs is very useful and suitable method for the study of protein-protein interaction.

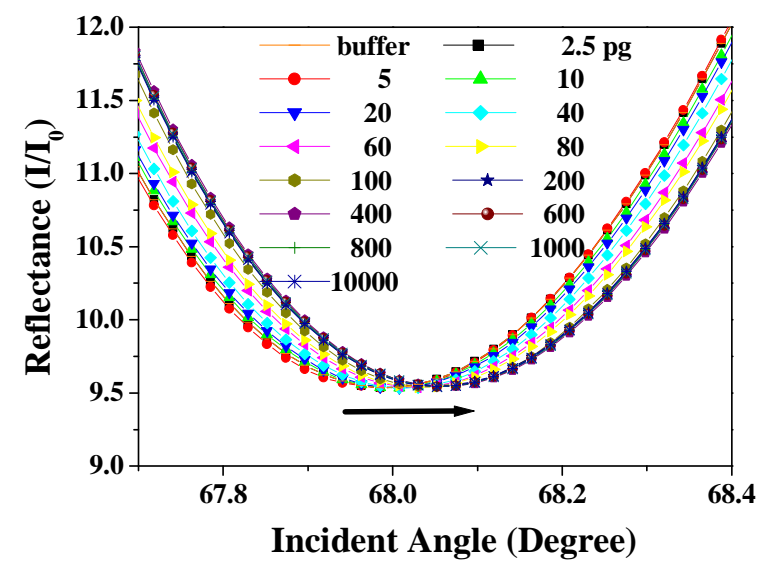

(a)

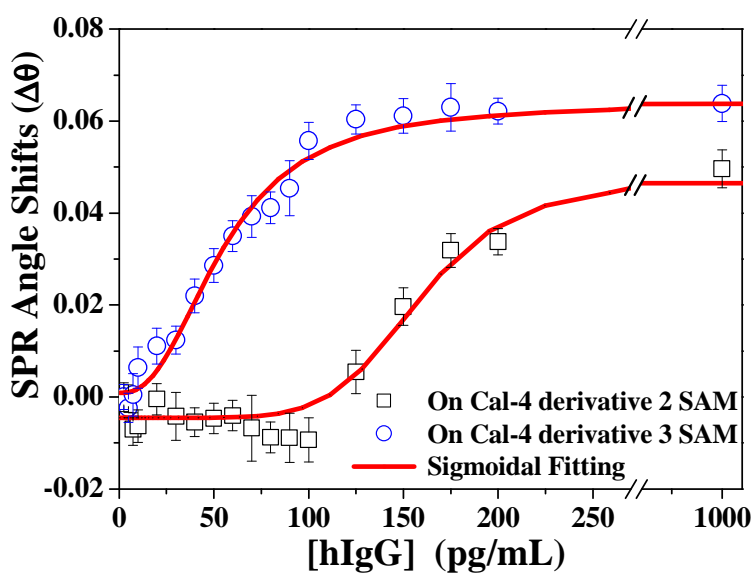

(b)

Figure 12. (a) SPR angle shifts according to the interaction between anti-hIgG and hIgG on the Cal-4 derivative 3 SAM. (b) Dose-response curves of anti-hIgG immobilized sensor chip represented by SPR angle shifts according to the interaction between anti-hIgG and hIgG on the Cal-4 derivative 2 (rectangular) and $\mathbf{3}$ (circle) SAMs. Solid line indicates the result of sigmoidal fitting.

\section{Conclusion}

In this study, three Cal-4 derivatives of which contain ethylester, carboxylic acid, and crownether as a functional group to interact with protein at the lower rim and a common reactive thiol at the upper rim were synthesized and constructed to monolayer on $\mathrm{Au}$ surface. The structural integrity and orientation of the Cal-4 derivative SAMs on the Au surface was characterized carefully. Surface 
confined Cal-4 derivatives have potential applications in the development of molecular linker layer for immobilizing protein by selective affinity at the surface. The interaction between BSA and surface confined Cal-4 derivative SAMs was analyzed by SPR and the surface concentration of immobilized BSA was theoretically calculated by simulation of experimental SPR data. The estimated surface concentration of BSA was the highest on the Cal-4 derivative 3 SAM with crownether group among the three Cal-4 linker systems. These results from SPR measurements indicate that the functional groups at the lower rim of Cal-4 exert a critical effect on the selective affinity toward the immobilizing protein in the SAMs. In addition, the SPR analysis for protein-protein interaction using anti-hIgG and $\mathrm{hIgG}$ was performed. From the results of SPR analysis, we confirmed that the detection of proteinprotein interaction at the very low concentration $(\mathrm{pg} / \mathrm{mL}$ level) is possible through the application of Cal-4 linker system to biochip and SPR detection system. In conclusion, the main results of this research showed that the SPR technique and careful construction of appropriate SAM are very useful methods to the development of more efficient biosensing interface.

\section{Acknowledgements}

This work was supported for two years by Pusan National University Research Grant and partially by the Brain Korea 21 project in 2007.

\section{References and Notes}

1. Vitalii, S.; Howard,W.; David, J. V. SPR Studies of the Nonspecific Adsorption Kinetics of Human IgG and BSA on Gold Surfaces Modified by Self-Assembled Monolayers (SAMs). J. Colloid Interface Sci. 1997, 185, 94-103.

2. Ji, H. F.; Brown, G. M.; Dabestani, R. Calix[4]arene-based $\mathrm{Cs}^{+}$selective optical sensor. Chem. Commun. 1999, 7, 609-610.

3. Bohmer, V. Calixarenes, Macrocycles with (Almost) Unlimited Possibilities. Angew Chemie 1995, 107, 785-818.

4. Koh, K.; Araki, K.; Shinkai, S.; Asfari, Z.; Vicens, J. Cation Binding Properties of a Novel 1,3Alternate Calix[4]biscrown. Formation of 1:1 and 1:2 Complexes and Unique Cation Tunneling across a Calix[4]arene Cavity. Tetrahedron Letters 1995, 36, 6095-6098.

5. Lo, H. S.; Yip, S. K.; Wong, K. M. C.; Zhu, N.; Yam, V. W. W. Selective Luminescence Chemosensing of Potassium Ions Based on a Novel Platinum (II) Alkynylcalix[4]crown-5 Complex. Organometallics 2006, 25, 3537-3540.

6. Doutea-guevel, N.; Coleman, A. W.; Morel, J. P.; Morel-Desrosiers, N. Complexation of the basic amino acids lysine and arginine by three sulfonatocalix[n]arenes $(n=4,6$ and 8$)$ in water: microcalorimetric determination of the Gibbs energies, enthalpies and entropies of complexation. J. Chem. Soc., Perkin Trans. II 1999, 3, 629-634.

7. Grote Gansey, M. H. B.; De Haan, A. S.; Bos, E. S.; Verboom, W.; Reinhoudt, D. N. Conjugation, Immunoreactivity, and Immunogenicity of Calix[4]arenes; Model Study to Potential Calix[4]arene-Based $\mathrm{Ac}^{3+}$ Chelators. Bioconjug. Chem. 1999, 10, 613-623.

8. Yilmaz, A.; Memon, S.; Yilmaz, M. Synthesis and study of allosteric effects on extraction behavior of novel calixarene-based dichromate anion receptors. Tetrahedron 2002, 58, 7735-7740. 
9. Memon, S.; Yilmaz, A.; Roundhill, D. M.; Yilmaz, M. Synthesis of Polymeric Calix[4]arene Dinitrile and Diamino-Derivatives: Exploration of Their Extraction Properties Towards Dichromate Anion. J. Macromolecular Sci., Part A. Pure and Applied Chemistry 2004, 41, 433447.

10. Tabakci, M.; Tabakci, B.; Yilmaz, M. Design and Synthesis of New Chiral Calix[4]arenes as Liquid Phase Extraction Agents for alfa-Amino Acid Methylesters and Chiral alfa-Amines. J. Incl. Phenom. Macrocycl. Chem. 2005, 53, 51-56.

11. Esplandiú, M. J.; Hagenström, H.; Kolb, D. M. Functionalized Self-Assembled Alkanethiol Monolayers on $\mathrm{Au}(111)$ Electrodes: 1. Surface Structure and Electrochemistry. Langmuir 2001, 17, 828-838.

12. O'Shannessy, D. J.; Brigham-Burke, M.; Peck, P. Immobilization chemistries suitable for use in the BIAcore surface plasmon resonance detector. Anal. Biochem. 1992, 205, 132-136.

13. Nelson, R. W.; Krone, J. R. Advances in surface plasmon resonance biomolecular interaction analysis mass spectrometry (BIA/MS). J. Mol. Recognit. 1999, 12, 77-93.

14. Gomes, P.; Giralt, E.; Andreu, D. Direct single-step surface plasmon resonance analysis of interactions between small peptide analytes and immobilised monoclonal antibodies. J. Immunol. Methods 2000, 325, 101-111.

15. Corsel, J. W.; Willems, G. M.; Kop, J. M. M.; Cuypers, P. A.; Hermens, W. T. The role of intrinsic binding rate and transport rate in the adsorption of prothrombin, albumin and fibrinogen to phospholipid bilayers. J. Colloid Interface Sci. 1986, 111, 544-554.

16. Iki, N.; Narumi, F.; Fujimoto, T.; Morohashi, N.; Miyano, S. Selective synthesis of three conformational isomers of tetrakis[(ethoxycarbonyl)methoxy]thiacalix[4]arene and their complexation properties towards alkali metal ions. J. Chem. Soc. Perkin Trans. 1998, 2, 27452750.

17. 1H NMR (400 MHz, DMF-d d $\left._{6}\right) \delta 6.72(\mathrm{~s}, 8 \mathrm{H}), 4.75$ (overlapped with $\mathrm{NH}_{2}$ ), $4.67(\mathrm{~s}, 8 \mathrm{H}), 4.16$ (s, 8 $\mathrm{H}), 4.12(\mathrm{q}, \mathrm{J}=6.6 \mathrm{~Hz}, 8 \mathrm{H}), 3.20(\mathrm{~d}, \mathrm{~J}=11.5 \mathrm{~Hz}, 4 \mathrm{H}), 1.20(\mathrm{t}, \mathrm{J}=6.6 \mathrm{~Hz}, 12 \mathrm{H}) ; 13 \mathrm{C}$ NMR (100 $\mathrm{MHz}_{\mathrm{CDCl}}$ ) $\mathrm{C}_{185.9}, 172.7,171.7,157.7,136.9,131.1,129.8,73.0,62.3,36.8,32.7,15.0$.

18. Kretschmann, E. Determination of optical constants of metals by excitation of surface plasmons. Phys. 1971, 241, 313-324.

19. Philips, A. V.; Robbins, D. J.; Coleman, M. S.; Barkley, M. D. Immunoaffinity purification and fluorescence studies of human adenosine deaminase. Biochemistry 1987, 26, 2893-2903.

20. Suri, C. R.; Jain, P. K.; Mishra, G. C. Development of piezoelectric crystal based microgravimetric immunoassay for determination of insulin concentration. J. Biotechnil. 1995, 39, 27-34.

21. Kanno, S.; Yanagida, Y.; Haruyama, T.; Kobatake, E.; Aizawa, M. Assembling of engineered IgGbinding protein on gold surface for highly oriented antibody immobilization. J. Biotechnol. 2000, 76, 207-214.

22. Whitesides, G. M.; Laibinis, P. E. Wet chemical approaches to the characterization of organic surfaces: self-assembled monolayers, wetting, and the physical-organic chemistry of the solidliquid interface. Langmuir 1990, 6, 87-96. 
23. Bryant, M. A.; Pemberton, J. E. Surface Raman scattering of self-assembled monolayers formed from 1-alkanethiols: behavior of films at gold and comparison to films at silver. J. Am. Chem. Soc. 1991, 113, 8284-8293.

24. Bard, A. J.; Faulkner, L. R. Electrochemical Methods; John Wiley \& Sons: New York, 2001; pp 239-243.

25. Walczak, M. M.; Popenoe, D. D.; Deinhammer, R. S.; Lamp, B. D.; Chung, C.; Porter, M. D. Reductive desorption of alkanethiolate monolayers at gold: a measure of surface coverage. Langmuir 1991, 7, 2687-2693.

26. Nonogaki, T.; Xu, S.; Kugimiya, S.; Sato, S.; Miyata, I.; Yonese, M. Two Dimensional AutoOrganized Nanostructure Formation of Hyaluronate on Bovine Serum Albumin Monolayer and Its Surface Tension. Langmuir 2000, 16, 4272-4278.

(C) 2007 by MDPI (http://www.mdpi.org). Reproduction is permitted for noncommercial purposes. 